\title{
Reactions of (-)-sparteine with alkali metal HMDS complexes: conventional meets the unconventional $\dagger$
}

\author{
Natalie M. Clark, Pablo García-Álvarez, Alan R. Kennedy, Charles T. O’Hara* \\ and Gemma M. Robertson
}

Received (in Cambridge, UK) 1st May 2009, Accepted 30th July 2009

First published as an Advance Article on the web 6th August 2009

DOI: $10.1039 / b 908722 b$

'Conventional' (-)-sparteine adducts of lithium and sodium 1,1,1,3,3,3-hexamethyldisilazide (HMDS) were prepared and characterised, along with an unexpected and 'unconventional' hydroxyl-incorporated sodium sodiate, [(-)-sparteine-Na$(\mu \text {-HMDS)Na.(-)-sparteine }]^{+}\left[\mathrm{Na}_{4}(\mu \text {-HMDS) })_{4}(\mathrm{OH})\right]^{-}$- the complex anion of which is the first inverse crown ether anion.

Alkyl and amido alkali metal reagents, in particular the respective lithium reagents, are amongst the most utilised compounds in synthesis. Indeed, $95 \%$ of all synthetic transformations for the pharmaceutical industry are thought to involve a lithium reagent at some stage. ${ }^{1}$ An all-pervading challenge for the synthetic chemist is the generation of optically-active compounds in good yield and selectivity. By incorporating a chiral diamine [such as (-)-sparteine] into alkyllithium systems, high levels of reactivity and stereoselectivity in deprotonation, oxidation, reduction and addition reactions $^{2-6}$ can be achieved. Surprisingly, the synthetic chemistry of chiral diamine complexes of alkali metal amides has been largely neglected, ${ }^{7}$ despite increased deprotonative selectivity of an amidolithium versus an alkyllithium towards certain organic substrates (nucleophilic addition is a common competing reaction for the latter).

Turning to solid-state chemistry, the (-)-sparteine adduct of a phosphorus-functionalised alkyllithium was reported in 1989 by Raston, White and coworkers. ${ }^{8}$ Recently, some key widelyutilised (-)-sparteine-coordinated organolithiums have been isolated and characterised by Strohmann et al., including the first monomeric butyllithium complex [(-)-sparteine. $\left.{ }^{t} \mathrm{BuLi}\right]{ }^{9,10}$ Again rather surprisingly, the solid-state chemistry of (-)-sparteine adducts of the alkali metal amides have thus far been neglected. Addressing this deficiency, we report here the synthesis and characterisation of the (-)-sparteine adducts of the synthetically important lithium and sodium bis(trimethylsilyl)amides (1 and $\mathbf{2}$, respectively). In addition, we report an intriguing, highly unusual hydroxyl-incorporated solvent-separated hexanuclear sodium sodiate complex (3) - a result which may perhaps shed light on the lack of research involving (-)-sparteine complexes of the alkali metal amides.

WestCHEM, Department of Pure and Applied Chemistry,

University of Strathclyde, Glasgow, UK G1 $1 X L$.

E-mail: charlie.ohara@strath.ac.uk; Tel: +44 (0)1415482667

$\dagger$ Electronic supplementary information (ESI) available: NMR data and space-filling diagrams. CCDC 730642 \& 730643. For ESI and crystallographic data in CIF or other electronic format see DOI: $10.1039 / \mathrm{b} 908722 \mathrm{~b}$
(-)-Sparteine-coordinated 1 was prepared by reacting $n$-butyllithium with an equimolar quantity of $\operatorname{HMDS}(\mathrm{H})$. This mixture was left to stir for $30 \mathrm{~min}$, then one molar equivalent of (-)-sparteine was added (Scheme 1). $\ddagger$ The solution was placed in a freezer $\left(-28^{\circ} \mathrm{C}\right)$ and X-ray quality crystals of $\mathbf{1}$, in moderate-to-good yield (64\%) were precipitated. In an attempt to prepare a sodium analogue of $\mathbf{1}, n$-butylsodium was utilised. After stirring the (-)-spartiene and metal amide solution for $30 \mathrm{~min}$, a crop of crystals precipitated at ambient temperature within one hour. To our surprise, X-ray crystallographic studies revealed that these crystals were not a simple (-)-sparteine adduct of NaHMDS, but an unusual hydroxyl-incorporated sodium sodiate, $\left[(-)\right.$-sparteine $\cdot \mathrm{Na}(\mu \text {-HMDS)Na.(-)-sparteine }]^{+}\left[\mathrm{Na}_{4}(\mu \text {-HMDS })_{4}{ }^{-}\right.$ $(\mathrm{OH})]^{-}$3, despite the apparent strict use of an inert atmosphere and Schlenk techniques.

This synthesis was deemed reproducible by checking the unit cell of several crystals from multiple batches of the crystalline material. It was assumed that the hydroxide contaminant arose from the reaction of the metal amide mixture with adventitious water which was present in the (-)-sparteine. When (-)-sparteine was subjected to a vacuum for two hours prior to use - in an attempt to remove volatiles such as entrained $\mathrm{H}_{2} \mathrm{O}-$ crystals of 3 were not forthcoming. Instead a microcrystalline material (2) precipitated from solution at $-28{ }^{\circ} \mathrm{C}$. Unfortunately, this material was not suitable for X-ray crystallographic analysis. However, by
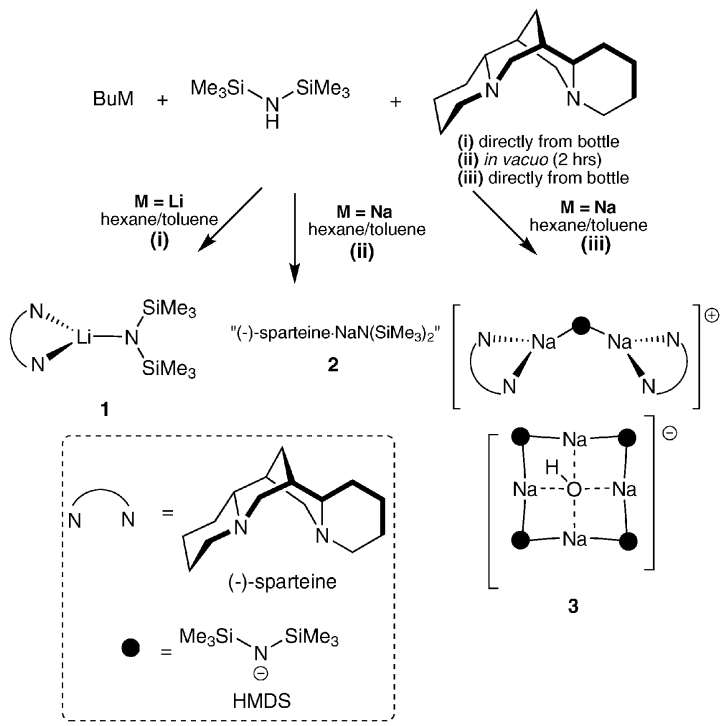

Scheme 1 Syntheses of 1, 2 and $\mathbf{3}$. 
${ }^{1} \mathrm{H}$ NMR analysis of $\mathbf{2}$ in $\mathrm{D}_{6}$-benzene solution, it was evident that the HMDS:(-)-spartiene ratio was $1: 1$ (akin to 1); different from the ratio for crystalline 3 in $\mathrm{D}_{6}$-benzene which was $5: 2$ (see $\mathrm{ESI} \dagger$ ). Crudely, these reactions show that if one molar equivalent of $\mathrm{H}_{2} \mathrm{O}$ is present, then it consumes six molar equivalents of NaHMDS to form 3 -possibly suggesting why (-)-sparteine solvates of alkali metal amides (in particular NaHMDS) have not yet been utilised to any significant degree in asymmetric synthesis. A lithium analogue of $\mathbf{3}$ could not be detected.

$\mathrm{X}$-Ray crystallographic studies reveal that $\mathbf{1}$ crystallises in the chiral space group $P 1$ and is monomeric in the solid-state (Fig. 1). Key bond parameters are given in the ESI. $\dagger$ Its $\mathrm{Li}$ centre is three-coordinate, adopting a distorted trigonal planar environment (sum of angles around $\mathrm{Li}, 356.2^{\circ}$ ). As expected the greatest distortion from perfect trigonal planarity occurs at the $(-)$-sparteine- $\mathrm{Li}$ bite angle $\left[89.9(2)^{\circ}\right]$. To the best of our knowledge, only three monomeric LiHMDS complexes have been published previously. These are a 12 -crown- $4,{ }^{11}$ a PMDETA ${ }^{12}$ $\left(N^{\prime}, N^{\prime}, N^{\prime \prime}, N^{\prime \prime}, N^{\prime \prime \prime}\right.$-pentamethyldiethylenetriamine and-perhaps most pertinent to this paper - a didentate TMEDA $\left(N^{\prime}, N^{\prime}, N^{\prime \prime}, N^{\prime \prime}\right.$-tetramethylethylenediamine) complex. $^{12}$ The $\mathrm{Li}-\mathrm{N}_{\text {HMDS }}$ bond distance in $\mathbf{1}$ [1.910(5) $\mathrm{A}$ ] is almost identical to that in the TMEDA complex [1.893(3) $\mathrm{A}]$. In 1, the (-)-sparteine coordinates to the $\mathrm{Li}$ centre symmetrically and the mean

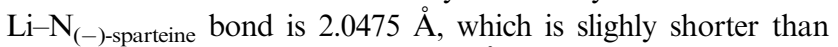
the mean $\mathrm{Li}-\mathrm{N}_{\text {TEMDA }}$ bond $(2.0805 \AA$ ) in the TMEDA adduct. The $\mathrm{N}_{\text {TMEDA }}-\mathrm{Li}-\mathrm{N}_{\text {TMEDA }}$ bite angle in this complex [87.6(1) $\AA$ ] is similar to the corresponding angle in $\mathbf{1}$ despite the much greater steric demands of the (-)-sparteine ligand. ${ }^{12}$ Collum has meticulously studied the solution chemistry of LiHMDS in the presence of more than 100 synthetically-useful and commonly employed ligands! ${ }^{13}$ Focusing on (-)-sparteine, his studies have shown that in hydrocarbon solution with a low concentration of the diamine present, the chelated monomer exists, with the exclusion of the solvated dimer or more highly solvated monomer, ${ }^{13,14}$ an observation which is in line with the solid state structure of $\mathbf{1}$.

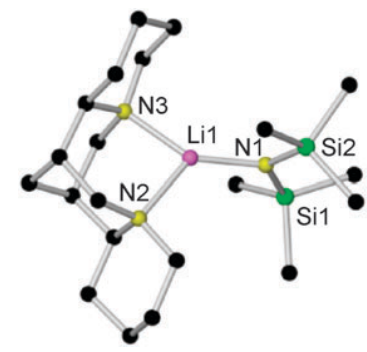

Fig. 1 Molecular structure of $\mathbf{1}$. $\mathrm{H}$ atoms are omitted for clarity.

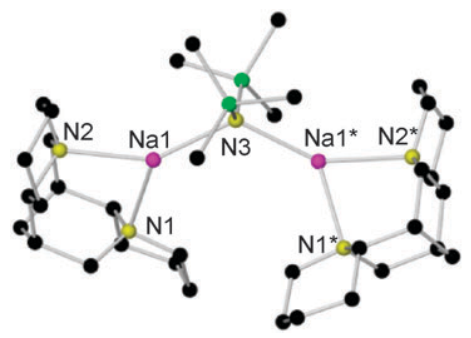

Fig. 2 Molecular structure of the cation of 3. H atoms are omitted for clarity.
$\mathrm{X}$-Ray crystallographic studies reveal that $\mathbf{3}$ crystallises in the chiral space group $C 2$, and due to its solvent separated ion pair composition, the cationic and anionic moieties of $\mathbf{3}$ will be discussed independently. Full crystallographic details are given in the ESI. $\dagger$ The cation (Fig. 2) contains two (-)-sparteine molecules which coordinate in the usual terminal fashion to two sodium atoms. To complete the structure of the cation, a HMDS anion bridges between the two metal centres, resulting in a distorted trigonal planar arrangement around $\mathrm{Na} 1$ (sum of angles, $354.1^{\circ}$ ). The only previously reported complex which incorporates both sodium and (-)-sparteine is $\left[(-)\right.$-sparteine $\left.\cdot \mathrm{NaMg}(\mathrm{TMP})_{2}{ }^{n} \mathrm{Bu}\right] .{ }^{15}$ The $\mathrm{Na}$ centre adopts a distorted tetrahedral geometry in this complex, as a consequence its mean $\mathrm{Na}-\mathrm{N}_{(-) \text {-sparteine bond distance }}$ $(2.4989 \AA)$ is slightly longer than that in the cation of 3 $(2.4255 \AA)$. This decrease in coordination number accompanies a slight widening of the diamine bite angle [from $72.59(6)^{\circ}$ to $74.9(2)^{\circ}$ in 3].

The anionic moiety of 3 (Fig. 3) consists of an almost perfectly planar eight-membered $\mathrm{Na}_{4} \mathrm{~N}_{4}$ ring [N4-N5-N6-N5* torsion angle is $0^{\circ}$; Na2-Na3-N3*-Na2* is $\left.-1.84(11)^{\circ}\right]$ which acts as a tetranuclear host towards a hydroxyl anion guest. This guest is disordered over two sites in the centre of the metal-amido ring (one above and one below the plane of the $\mathrm{Na}_{4} \mathrm{~N}_{4}$ ring, vide infra). The mean $\mathrm{Na}-\mathrm{O}$ bond length is $2.336 \AA$. In addition to the $\mathrm{Na}-\mathrm{O}$ bonding within the structure, each $\mathrm{Na}$ atom is bonded to two amido- $\mathrm{N}$ centres. The mean 'corner' $\mathrm{Na}-\mathrm{N}-\mathrm{Na}$ and 'side' $\mathrm{N}-\mathrm{Na}-\mathrm{N}$ angles of the octa-atomic ring are 81.06 and $170.96^{\circ}$, respectively.

The structures of other discrete $(\mathrm{Na}-\mathrm{N})_{4}$ eight-membered rings have been published by Veith et al. ${ }^{16}$ These sodium amides, [\{ $\left.\left.\mathrm{RNSiMe}_{2} \mathrm{OSiMe}_{2} \mathrm{NR}\right\}_{2} \mathrm{Na}_{4}\right]$ (where $\mathrm{R}$ is ${ }^{t} \mathrm{Bu}$ or $\mathrm{SiMe}_{3}$ ) adopt fundamentally different structures from that of the anion of 3. Firstly, the rings in Veith's complexes deviate significantly from planarity, the $\mathrm{Na}$ atoms are stabilised by internal chelation, and of course, these complexes are electronically neutral. Donor-free NaHMDS has been isolated in the solid state as polymeric ${ }^{17}$ and cyclic trimeric ${ }^{18,19}$ polymorphs, possibly indicating that other oligomers of NaHMDS (perhaps a cyclic tetramer akin to donor-free NaTMP, ${ }^{20}$ TMP is 2,2,6,6-tetramethylpiperidide) may exist in solution. Despite the incorporation of $\mathrm{OH}^{-}$, the mean $\mathrm{Na}-\mathrm{N}$ bond distance in the anion of $\mathbf{3}(2.398 \AA)$ is essentially

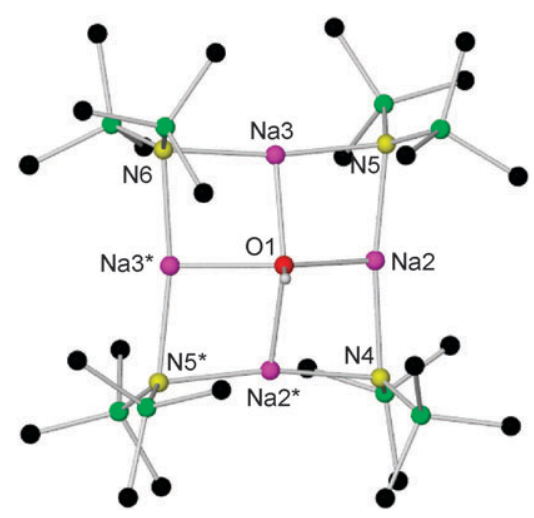

Fig. 3 Molecular structure of the anion of 3. H atoms (except for $\mathrm{O} H$ ) and disorder component have been omitted for clarity. 
identical to that in polymeric ${ }^{17}$ and cyclic $^{18,19}$ NaHMDS polymorphs (2.381 and $2.350 \AA$, respectively); the mean $\mathrm{N}-\mathrm{Na}-\mathrm{N}$ and $\mathrm{Na}-\mathrm{N}-\mathrm{Na}$ angles (100.07 and $139.70^{\circ}$, respectively) are approximately $20^{\circ}$ wider and $30^{\circ}$ narrower than their respective counterparts in the anion of 3 . This anion can be directly compared to a cationic crown ether complex. Whereas a neutral crown ether molecule encaptures a metal cation to become a cationic species, here the 'NaHMDS tetramer' encapsulates a hydroxyl ligand forming the anion of 3 . In keeping with the chemistry and terminology developed by Mulvey et al. ${ }^{21-23}$ this anion can be considered as the first anionic inverse crown ether. It is presumably isolable due to the immense steric bulk of (-)-sparteine which sufficiently stabilises the counter-cation of 3 (see ESI $\dagger$ ).

Due to the large number of chemically distinct aliphatic $\mathrm{H}$ and $\mathrm{C}$ atoms in (-)-sparteine, the ${ }^{1} \mathrm{H}$ and ${ }^{13} \mathrm{C}$ NMR spectra for 1-3 are extremely complex (see ESI $\dagger$ ). The key feature in all three spectra are that the resonances due to the diamine ligand are broader and differ slightly from those associated with the free diamine; hence, $(-)$-sparteine appears to remain at least partially coordinated to the respective metal centres in arene solution. For 3, only one resonance is observed for the HMDS group, despite there being two chemically distinct ligands in the solid-state structure. This may not be too surprising given the similar local coordination environment of the different HMDS groups (in both the cation and anion HMDS bridges in a $\mu_{2}$-fashion to two $\mathrm{Na}$ atoms). Low temperature NMR studies proved futile in resolving the two distinct HMDS resonances.

To summarise, we have opened a new frontier in alkali metal HMDS chemistry by incorporating (-)-sparteine, and at the same time identified a problem that could occur if necessary purification procedures are not employed. In addition, we have prepared the first anionic inverse crown structure, which should pave the way for the development of a new Group 1 macrocyclic/supramolecular chemistry.

The authors thank D. V. Graham (X-ray crystallography) and the EPSRC (grant award no. EP/F065833/1) for generously sponsoring this research. This research was also supported by a Marie Curie Intra European Fellowship within the 7th European Community Framework Programme (to PGA).

\section{Notes and references}

$\ddagger$ All reactions were carried out under a protective argon atmosphere. Synthesis of [(-)-sparteine LiHMDS] (1): ${ }^{n} \mathrm{BuLi}(1.25 \mathrm{~mL}$ of a $1.6 \mathrm{M}$ solution in hexanes, $2 \mathrm{mmol}$ ) was added to $5 \mathrm{~mL}$ of dried hexane in a Schlenk tube. HMDS(H) $(0.42 \mathrm{~mL}, 2 \mathrm{mmol})$ was added and the mixture was allowed to stir for $30 \mathrm{~min}$, after which (-)-sparteine $(0.46 \mathrm{~mL}, 2 \mathrm{mmol})$ was added. The colourless solution was reduced in volume by approximately $50 \%$ and placed in a freezer which was operating at $-28^{\circ} \mathrm{C}$. After $48 \mathrm{~h}$, small colourless X-ray quality crystals of 1 were deposited $(0.51 \mathrm{~g}, 64 \%)$. ${ }^{1} \mathrm{H}$ NMR $(400.13 \mathrm{MHz}, 300 \mathrm{~K}$, $\left.\mathrm{C}_{6} \mathrm{D}_{5} \mathrm{CD}_{3}\right): \delta 3.16,2.78,2.53,2.33,2.28,1.81,1.71,1.5,1.44,1.32$, $1.22,1.03,0.89,0.62,0.35 \mathrm{ppm}\left(\mathrm{SiCH}_{3}\right) .{ }^{13} \mathrm{C}$ NMR $(100.63 \mathrm{MHz}$, $\left.300 \mathrm{~K}, \mathrm{C}_{6} \mathrm{D}_{5} \mathrm{CD}_{3}\right): \delta 67.6,61.8,60.3,58.3,54.4,46.5,35.8,35.6,30.4$, 29.0, 25.6, 25.2, 24.9, 24.7, 18.6, 7.5 ppm. ${ }^{7} \mathrm{Li}$ NMR (155.47 MHz, $\left.300 \mathrm{~K}, \mathrm{C}_{6} \mathrm{D}_{5} \mathrm{CD}_{3}\right): \delta 1.50 \mathrm{ppm}$.

Synthesis of "[(-)-sparteine-NaHMDS]" (2): "BuNa (0.16 g, $2 \mathrm{mmol}$ ) was suspended in $5 \mathrm{~mL}$ of dried hexane in a Schlenk tube.
HMDS(H) $(0.42 \mathrm{~mL}, 2 \mathrm{mmol})$ was added and allowed to stir for $30 \mathrm{~min}$, after which (-)-sparteine $(0.46 \mathrm{~mL}, 2 \mathrm{mmol})$, which had been subjected to vaccum for two hours, and toluene $(1 \mathrm{~mL})$ were added. The colourless solution was placed in a freezer (operating at $-28{ }^{\circ} \mathrm{C}$ ). After $24 \mathrm{~h}$, a colourless microcrystalline material (2) deposited [0.22 g, 26\% (first batch)]. ${ }^{1} \mathrm{H}$ NMR $\left(400.13 \mathrm{MHz}, 300 \mathrm{~K}, \mathrm{C}_{6} \mathrm{D}_{6}\right): \delta$ $2.77,2.66,2.47,2.26,2.14,2.08,1.95,1.85,1.62,1.54,1.41,1.37,1.23$, $1.10,1.00,0.15 \mathrm{ppm}\left(\mathrm{SiCH}_{3}\right)$.

Synthesis of $[(-) \text {-sparteine } \cdot \mathrm{Na}(\mu-\mathrm{HMDS}) \mathrm{Na} \cdot(-) \text {-sparteine }]^{+}\left[\mathrm{Na}_{4}-\right.$ $\left.(\mu-\mathrm{HMDS})_{4}(\mathrm{OH})\right]^{-}(3):{ }^{n} \mathrm{BuNa}(0.16 \mathrm{~g}, 2 \mathrm{mmol})$ was suspended in $5 \mathrm{~mL}$ of dried hexane in a Schlenk tube. $\operatorname{HMDS}(\mathrm{H})(0.42 \mathrm{~mL}, 2 \mathrm{mmol})$ was added and the mixture was allowed to stir for $30 \mathrm{~min}$, after which 'non-dried' (-)-sparteine $(0.46 \mathrm{~mL}, 2 \mathrm{mmol})$ and toluene $(1 \mathrm{~mL})$ were added. After stirring for one hour, crystals of $3[0.12 \mathrm{~g}, 25 \%$ (first batch)] deposited at ambient temperature. ${ }^{1} \mathrm{H}$ NMR $(400.13 \mathrm{MHz}$, $\left.300 \mathrm{~K}, \mathrm{C}_{6} \mathrm{D}_{5} \mathrm{CD}_{3}\right): \delta 2.77,2.66,2.48,2.30,2.13,2.06,1.95,1.86,1.69$ $1.53,1.42,1.39,1.25,1.14,1.11,1.01,0.48(\mathrm{OH}), 0.13\left(\mathrm{SiCH}_{3}\right)$.

Crystal data for 1: $\mathrm{C}_{21} \mathrm{H}_{44} \mathrm{LiN}_{3} \mathrm{Si}_{2}, M_{r}=401.71$, triclinic, space group $P 1, a=7.6371(3), b=9.1030(3), c=10.5163(4) \AA, \alpha=$ 111.657(2), $\beta=106.120(2), \gamma=97.915(2)^{\circ}, V=628.71(4) \AA^{3}, Z=1$, $\lambda=0.71073 \AA, \mu=0.151 \mathrm{~mm}^{-1}, T=123(2) \mathrm{K} ; 15393$ reflections, 5224 unique, $R_{\text {int }}=0.050$; final refinement to convergence on $F^{2}$ gave $R=0.0504\left(F, 4570\right.$ obs. data only) and $R_{\mathrm{w}}=0.1416\left(F^{2}\right.$, all data), $\mathrm{GOF}=1.091$. Absolute configuration confirmed by refinement of Flack parameter to $-0.08(12)$.

Crystal data for 3: $\mathrm{C}_{60} \mathrm{H}_{143} \mathrm{~N}_{9} \mathrm{Na}_{6} \mathrm{OSi}_{10}, M_{r}=1425.67$, monoclinic, space group $C 2, a=18.2491(4), b=16.2717(3), c=14.9831(3) \AA$, $\beta=90.450(2)^{\circ}, V=4449.00(16) \AA^{3}, Z=2, \lambda=1.54184 \AA, \mu=$ $1.973 \mathrm{~mm}^{-1}, T=123(2) \mathrm{K} ; 13781$ reflections, 6757 unique, $R_{\text {int }}=$ 0.0212 ; final refinement to convergence on $F^{2}$ gave $R=0.0435$ $\left(F, 5176\right.$ obs. data only) and $R_{\mathrm{w}}=0.1083\left(F^{2}\right.$, all data $), \mathrm{GOF}=$ 0.926 . Absolute configuration confirmed by refinement of Flack parameter to $-0.03(3)$. The $\mathrm{OH}$ group is modelled as disordered over two sites, occupancy $50: 50 . \dagger$

1 D. B. Collum, Acc. Chem. Res., 1993, 26, 227

2 J.-C. Kizirian, Chem. Rev., 2008, 108, 140.

3 P. O'Brien, J. Chem. Soc., Perkin Trans. 1, 1998, 1439.

4 D. Hoppe and T. Hense, Angew. Chem., Int. Ed. Engl., 1997, 36, 2282.

5 M. R. Luderer, W. F. Bailey, M. R. Luderer, J. D. Fair, R. J. Dancer and M. B. Sommer, Tetrahedron: Asymmetry, 2009, DOI: $10.1016 /$ j.tetasy.2009.1003.1015.

6 L. M. Engelhardt, W.-P. Leung, C. L. Raston, G. Salem, P. Twiss and A. H. White, J. Chem. Soc., Dalton Trans., 1988, 2403.

7 H. Doi, T. Sakai, M. Iguchi, K.-I. Yamada and K. Tomioka, J. Am. Chem. Soc., 2003, 125, 2886.

8 L. T. Byrne, L. M. Engelhardt, G. E. Jacobsen, W.-P. Leung, R. I. Papasergio, C. L. Raston, B. W. Skelton, P. Twiss and A. H. White, J. Chem. Soc., Dalton Trans., 1989, 105.

9 V. H. Gessner, C. Däschlein and C. Strohmann, Chem.-Eur. J., $2009, \mathbf{1 5}, 3320$

10 C. Strohmann and V. H. Gessner, Angew. Chem., Int. Ed., 2007, 46, 4566.

11 P. P. Power and X. J. Xu, J. Chem. Soc., Chem. Commun., 1984, 358.

12 K. W. Henderson, A. E. Dorigo, Q.-L. Liu and P. G. Willard, J. Am. Chem. Soc., 1997, 119, 11855.

13 B. L. Lucht and D. B. Collum, Acc. Chem. Res., 1999, 32, 1035.

14 B. L. Lucht, M. P. Bernstein, J. F. Remenar and D. B. Collum, J. Am. Chem. Soc., 1996, 118, 10707.

15 A. R. Kennedy and C. T. O'Hara, Dalton Trans., 2008, 4975.

16 M. Veith, S. Wieczorek, K. Fries and V. Huch, Z. Anorg. Allg. Chem., 2000, 626, 1237.

17 R. Grüning and J. L. Atwood, J. Organomet. Chem., 1977, 137, 101.

18 M. Driess, H. Pritzkow and M. Skipinski, Organometallics, 1997, 16, 5108.

19 J. Knizek, I. Krossing, H. Nöth, H. Schwenk and T. Seifert, Chem. Ber., 1997, 130, 1053

20 B. Gehrhus, P. H. Hitchcock, A. R. Kennedy, M. F. Lappert, R. E. Mulvey and P. J. A. Rodger, J. Organomet. Chem., 1999, 587, 88.

21 R. E. Mulvey, F. Mongin, M. Uchiyama and Y. Kondo, Angew. Chem., Int. Ed., 2007, 46, 3802.

22 R. E. Mulvey, Organometallics, 2006, 25, 1060.

23 R. E. Mulvey, Acc. Chem. Res., 2009, 42, 743. 